\title{
WAR CONCEPTION IN ARTISTIC AND PUBLICIST WORKS OF LEO TOLSTOY: SPECIFICITY OF LINGUISTIC REPRESENTATION
}

\author{
Grigory V. Tokarev \\ Tula State Lev Tolstoy Pedagogical University, Tula, Russia
}

\begin{abstract}
The article highlights distinctive features of war representation that is considered to be crucial in artistic and publicist works of Leo Tolstoy. The concept particularity is manifested in the writer's lexicon against the background of the $19^{\text {th }}$ stereotypes and conventions. It is stated that the inherent nature of the concept is encoded in words sumasshestviye (madness), zlo (evil), nasiliye (violence), and the idea gets its conceptualization by being denied, Leo Tolstoy considers it an unnatural power that contradicts human existence laws. However, in his early works Tolstoy used to appreciate people's war for liberation, which in his late works was totally rejected - the writer and publicist called it manifestation of evil and violence, his evaluation of patriotism in military actions changed to complete negation. The concept constituents and their linguistic representations are described and shaped in evolutionary mental and sign series.

The article presents some fragment of the writer's worldview in which the war is seen as a consequence of state institutions activity. Being firstly stated in Tolstoy's literary works, it was then transferred to the publicist writings where he could openly and clearly express his opinion, and the writer's lexicon there becomes less figurative and elusive but more explicitly and direct.

Key words: concept, Leo Tolstoy, war, conceptualization, categorization, lexicon.

Citation. Tokarev G.V. War Conception in Artistic and Publicist Works of Leo Tolstoy: Specificity of Linguistic Representation. Vestnik Volgogradskogo gosudarstvennogo universiteta. Seriya 2, Yazykoznanie [Science Journal of Volgograd State University. Linguistics], 2017, vol. 16, no. 4, pp. 121-128. (in Russian). DOI: https://doi.org/ 10.15688/jvolsu2.2017.4.10
\end{abstract}

\section{ОСОБЕННОСТИ ЯЗЫКОВОГО ВОПЛОЩЕНИЯ ПРЕДСТАВЛЕНИЙ О ВОЙНЕ В ХУДОЖЕСТВЕННОМ И ПУБЛИЦИСТИЧЕСКОМ ТВОРЧЕСТВЕ \\ Л.Н. ТОЛСТОГО}

\author{
Григорий Валериевич Токарев \\ Тульский государственный педагогический университет им. Л.Н. Толстого, г. Тула, Россия
}

\footnotetext{
Аннотация. В статье рассмотрены особенности репрезентации представлений о войне в художественном и публицистическом творчестве Л.Н. Толстого. Концепт Война является ключевым для творчества писателя. Специфика концептуализации войны в произведениях Л.Н. Толстого показана на фоне существовавших в XIX в. стереотипов и установок. Описан лексикон, воплощающий данную тему. Для выражения сущности 흘 концепта Война писатель использует слова сумасшествие, зло, насилие. Процесс концептуализации войны ㄱ. в творчестве Л.Н. Толстого осуществляется с опорой на ментальную константу: на протяжении всего творчества писатель отрицает войну, понимает ее как противоестественную силу, действующую вопреки законам \% жизни. Однако если в ранних произведениях Л.Н. Толстой поддерживал войну народную и освободительную, то в поздних - считал любую войну проявлением зла, насилия, негативно оценивал деятельность военного, п् патриотизм. Знания, включенные в концепт, и их репрезентации описаны в виде эволюционных ментальных (2) и знаковых рядов.
} 


\section{РАЗВИТИЕ И ФУНКЦИОНИРОВАНИЕ РУССКОГО ЯЗЫКА}

Представлен фрагмент концептосферы писателя, в которой война является следствием деятельности институтов власти и государства. Репрезентация воззрений на войну переносится Л.Н. Толстым из художественного творчества в публицистику, которая позволяла мыслителю точно, однозначно, прямо выразить свою позицию. Лексикон писателя, репрезентирующий данные представления, становится менее фигуральным и оценочным, но более категоричным.

Ключевые слова: концепт, Л.Н. Толстой, война, концептуализация, категоризация, лексикон.

Цитирование. Токарев Г. В. Особенности языкового воплощения представлений о войне в художественном и публицистическом творчестве Л.Н. Толстого // Вестник Волгоградского государственного университета. Серия 2, Языкознание. - 2017. - Т. 16, № 4. - C. 121-128. - DOI: https://doi.org/10.15688/jvolsu2.2017.4.10

\section{1}

Концепт Война является базовым в творчестве Л.Н. Толстого. В произведениях писателя рефлексии подлежит война на Кавказе, в Крыму в середине 50-х гг. XIX в., Отечественная война 1812 г., русско-японская война в начале XX века. Активная гражданская позиция писателя обусловила обращение к теме войны на протяжении всего творчества.

Цель данной статьи заключается в выявлении специфики репрезентации представлений Л.Н. Толстого о войне. Результаты проведенного исследования расширяют теорию концептуализации и категоризации знания, индивидуального концепта, имеют прикладное значение, поскольку особенности толстовского понимания войны рассматриваются в эволюционном аспекте.

Специфика концептуализации войны в творчестве Л.Н. Толстого проявляется на фоне сушествовавших в XIX в. стереотипов, установок [Краткий словарь когнитивных терминов, 1996, с. 177]. Война в представлениях офицера того времени была своеобразным развлечением, средством развеять скуку, заслужить пожизненное общественное признание, популярность у женщин. В подтверждение этого достаточно вспомнить персонажей романа М.Ю. Лермонтова «Герой нашего времени». Личность офицера в русской литератуpe, в том числе и в произведениях Л.Н. Толстого, была окружена романтическим ореолом, апеллировала к лингвокультурным типажам [Карасик, Дмитриева, 2005, с. 8] защитников, стражей правды и справедливости. Культурные установки XIX в. определяли военную службу как концепт с высоким социальным рейтингом [Степанов, 2001, с. 40].

Процесс концептуализации войны в творчестве Л.Н. Толстого осуществляется с опо- рой на ментальную константу: на протяжении всего творчества писатель отрицает войну, понимает ее как противоестественную силу, действующую вопреки законам жизни. Война характеризуется словами и словосочетаниями сумасшествие, противное человеческому разуму и всей человеческой природе событие, зло, убийство, предопределяющими когнитивные стратегии понимания данного социального феномена. Объяснение войны с опорой на слова зло и сумасшествие детерминируют особенности стратегий ее концептуализации: открытая негативная оценочность и алогизм, построенный на контрасте должного и реального. Однако представления Толстого о войне, несмотря на существование стабильной части, на протяжении творчества существенно изменяются. Тем самым знания, включенные в концепт, и их репрезентации допускают описание в виде эволюционных ментальных и знаковых рядов [Степанов, 2001, с. 61 ; Токарев, 2003, с. 52].

\section{2}

Первым воплощением представлений о войне стали «Севастопольские рассказы». В них концепт Война получил отчетливую параметризацию. По художественной версии автора, война имеет две стороны: внешнюю, праздничную, парадную, и внутреннюю-мучительную, жестокую, кровавую:

увидите войну не в правильном, красивом и блестящем строе, с музыкой и барабанным боем, с развевающимися знаменами и гарцующими генералами, а увидите войну в настоящем ее выражении - в крови, в страданиях, в смерти... (Севастопольские рассказы, с. 9).

Для выражения своего понимания сути войны автор использует контекстуальные 
антонимы [Апресян, 1995, с. 285] для того, чтобы показать противоречивый характер войны. Причем «неправильная» сторона войны характеризуется как настоящая, правдивая.

Осмысление феномена войны осуществляется в аспекте объяснения ее роли для общества в целом и для отдельного человека. Документальная точность позволяет писателю убедительно выразить разрушительную и уничтожающую функцию войны. Однако Толстого, как психолога, больше интересует влияние войны на внутренний мир человека. Она объединяет людей, заставляет их сделать, нередко неосознанно, нравственный выбор, проявить «твердость духа». Концепт Война в «Севастопольских рассказах» осмысляется в тесной связи с концептом Патриотизм. Толстой приходит к мысли о том, что важной внутренней силой войны является чувство патриотизма, которое побуждает человека принять тяжелые условия, пойти на смерть ради своей родины:

И эта причина есть чувство, редко проявляющееся, стыдливое в русском, но лежащее в глубине души каждого, - любовь к родине (Севастопольские рассказы, с. 16).

Определение патриотизма с опорой на слова редкий, стылдивый, лежащий в глубине, душа, родина обусловливает его положительную интерпретацию. Патриотизм осмысляется Толстым как нравственный феномен, как важный внутренний фактор, дающий человеку смысл жизни. Тем самым война находит моральное оправдание.

Война позволяет увидеть черты национального характера, а именно: простоту, упрямство, чувство собственного достоинства:

Вглядитесь в лица, в осанки и в движения этих людей: в каждой морщине этого загорелого скуластого лица, в каждой мышце, в ширине этих плеч, в толщине этих ног, обутых в громадные сапоги, в каждом движении, спокойном, твердом, неторопливом, видны эти главные черты, составляющие силу русского, - простоты и упрямства (Севастопольские рассказы, с. 14).

«Толстой, отрицая войну как средство решения конфликтов, воспевает подвиг защитников родины» [Волчек, 2011, с. 256].
В романе-эпопее «Война и мир» получает развитие еще один аспект войны. Толстой размышляет о движущей силе истории. Формально, внешне она выражается в установлении влияния одного государства на другое в результате войн. Однако, по мнению Толстого, существуют невидимые, но более значимые силы, влияющие на ход истории:

...сила, решающая участь народов, лежит не в завоевателях, даже не в армиях и сражениях, а в чемто другом (Война и мир, с. 120).

Этой силой является народ, защищающий свою Родину и играющий «не по правилам»:

Сожжение городов и деревень, отступление после сражений, удар Бородина и опять отступление, пожар Москвы, ловля мародеров, переимка транспортов, партизанская война - все это были отступления от правил (Война и мир, с. 120).

Эту необузданную силу народного сопротивления, выражаемую партизанской войной, Л.Н Толстой фигурально называет дубиной народной войны:

...Дубина народной войны поднялась со всею своею грозною и величественною силой и, не спрашивая ничьих вкусов и правил, с глупою простотой, но с целесообразностью, не разбирая ничего, поднималась и опускалась и гвоздила французов, пока не погибло все нашествие (Война и мир, с. 120).

Таким образом, Толстой, в целом отрицая войну как убийство и разрушение, объясняя ее как сумасшествие и противоречие всем умственным и нравственным законам, признает, одобряет войну освободительную, которую ведет сам народ, а не полководцы, «войну без правил», а потому непредсказуемую, стихийную. Такая война Толстым понимается как акт восстановления исторической справедливости.

Итак, в «Севастопольских рассказах» и «Войне и мире» Толстой показывает противоречивый характер войны, ее лицевую и изнаночную стороны. Характеризуя войну как зло, Толстой отмечает те положительные следствия, которые она может иметь: объединять людей, раскрывать патриотические чувства, проявлять особенности национальной рефлексии. Исключением из принципа отрицания войны является война освободительная, народная. 
3

Перелом мировоззрения Л.Н. Толстого в 80-е годы затронул и представления писателя о войне, которые отражены прежде всего в многочисленных статьях, а также отчасти в повести «Хаджи Мурат». Примечательно, что в ее основу положены события того же исторического периода - 50-е годы, который был изображен в «Севастопольских рассказах», однако русская военная кампания на Кавказе показана с немалой долей цинизма. Для выражения данной интенции Толстой употребляет лексику с противоречащим денотативно-сигнификативным содержанием [Алефиренко, 1999, с. 92], что приводит к алогизму. Так, Толстой изображает цинизм и жестокость действий императора. Николай Первый определяет форму наказания польского студента, напавшего на профессора после проваленного экзамена и нанесшего ему «несколько ничтожных ран»:

Заслуживает смертной казни. Но, слава богу, смертной казни у нас нет. И не мне вводить ее. Провести 12 раз скрозь тысячу человек, Николай», подписал он с своим неестественным, огромным росчерком. Николай знал, что двенадцать тысяч шпицрутенов была не только верная, мучительная смерть, но излишняя жестокость, так как достаточно было пяти тысяч ударов, чтобы убить самого сильного человека (Хаджи Мурат, с. 72).

Прием противопоставления используется при описании разрушительных действий солдат царской армии:

Вернувшись в свой аул, Садо нашел свою саклю разрушенной: крыша была провалена, и дверь и столбы галерейки сожжены, и внутренность огажена. Сын же его, тот красивый, с блестящими глазами мальчик, который восторженно смотрел на ХаджиМурата, был привезен мертвым к мечети на покрытой буркой лошади. Он был проткнут штыком в спину. Благообразная женщина, служившая, во время его посещения, Хаджи-Мурату, теперь, в разорванной на груди рубахе, открывавшей ее старые, обвисшие груди, с распущенными волосами, стояла над сыном и царапала себе в кровь лицо и не переставая выла. ... два стожка сена были сожжены; были поломаны и обожжены посаженные стариком и выхоженные абрикосовые и вишневые деревья и, главное, сожжены все ульи с пчелами (Хаджи Мурат, с. 80).
Для увеличения степени экспрессии используется оценочная лексика с семой 'разрушение': провалены, сожжены, огажены, поломаны и др. Очевидно, что писатель рассчитывал на когнитивный диссонанс, рисуя сцены, которые вступают в противоречие с традицией изображать в положительном свете русского солдата.

Результат действий царской армии Толстой подчеркивает в описании внутреннего состояния мирных чеченцев после совершенного на их поселение набега:

Это была не ненависть, а непризнание этих русских собак людьми и такое отвращение, гадливость и недоумение перед нелепой жестокостью этих существ, что желание истребления их, как желание истребления крыс, ядовитых пауков и волков, было таким же естественным чувством, как чувство самосохранения (Хаджи Мурат, с. 81).

Толстой пытается охарактеризовать внутренне состояние героев путем отрицания слова, которое могло бы выразить ожидаемую у людей эмоцию, оказавшихся в подобной ситуации (не ненависть), и подбора взаимно уточняющих контекстуальных синонимов (непризнание людьми, гадливость, недоумение перед жестокостью). Обращает на себя внимание лексикон, который использует писатель, давая оценку действиям солдат, прежде всего инвективные, уничижительные слова. Писатель приходит к выводу о том, что склонность к уничтожению и разрушению лежит в основе природы человека:

Экое разрушительное, жестокое существо человек, сколько уничтожил разнообразных живых существ, растений для поддержания своей жизни (Хаджи Мурат, с. 6).

Любая война, в понимании Толстого, не может быть оправдана, поскольку она есть зло и насилие. «Вопрос о войне для Толстого был едва ли не важнейшей частью глобальной проблемы о насилии над человеческой личностью» [Захаров, 2016, с. 211]. Его идеи схожи с мыслями одной из героинь повести - Марьи Дмитриевны, увидевшей отрезанную голову убитого Хаджи Мурата: Bсе вы живорезы. На возражение офицера Бутлера о том, что на войне такие законы, война есть война, се- 
годня ты, а завтра тебя, Марья Дмитриевна безапелляционно отвечает:

Война! Какая война? Живорезы, вот и все (Хаджи Мурат, с. 110).

\section{4}

В публицистических произведениях Толстого конца 90-х - начала 900-х гг. война осуждается во всех формах ее проявления, поскольку она нарушает христианскую заповедь не убий, а значит, не может быть оправдана. Толстой отказывается от мысли, что война объединяет людей. В статье «Не убий никого» от пишет:

Животные могут быть соединены насилием, но люди могут соединяться только одним общим для всех пониманием жизни (Не убий никого, с. 49).

Новым аспектом концептуализации становится отрицательная оценка военной службы, избираемой как по доброй воле, так и по принуждению. Для определения данного вида деятельности писатель использует оценочные прилагательные: гадкое и преступное дело. Отрицательную оценку деятельности военного, диссонирующую с образами русских офицеров из «Севастопольских рассказов» и «Войны и мира», подчеркивает сравнение военного с палачом:

...военное дело ... есть дело столь же и даже гораздо более постыдное, чем дело и звание палача, так как палач признает себя готовым убивать только людей, признанных вредными и преступниками, военный же человек обещается убивать и всех тех людей, которых только ему велят убивать... (Доклад, с. 123).

Людей, занятых военным делом, Толстой цинично называет пушечным мясом, указывая на то, что война не делает различий между людьми, пожирает их.

И одуренные молитвами, проповедями, воззваниями, процессиями, картинами, газетами, пушечное мясо, сотни тысяч людей однообразно одетые, с разнообразными орудиями убийства, оставляя родителей, жен, детей, с точкой на сердце, но с напущенным молодечеством, едут туда, где они, рискуя смертью, будут совершать самое ужасное дело: убийство людей, которых они не знают и которые им ничего дурного не сделали. И за ними едут врачи, сестры милосердия, почему-то полагающие, что дома они не могут служить простым, мирным, страдающим людям, а могут служить только тем людям, которые заняты убийством друг друга. Остающиеся же дома радуются известиям об убийстве людей и, когда узнают, что убитых японцев много, благодарят за это когото, кого они называют Богом (Доклад, с. 106).

Данный отрывок репрезентирует трактовку войны как сумасшествия, построенную на контрасте между должным и реальным. Отцы должны заниматься содержанием своих семей и воспитанием своих детей, но они бросают их; люди убивают других людей, благодарят Бога за убийства и т. д. Для выражения своих мыслей Толстой использует тактику буквального объяснения и изменения угла зрения на события (подробно такая тактика описана в: [Рикёр, 2012]).

Меняются взгляды Толстого и на патриотизм. Выделяя разные его виды (завоевательный, удержательный и восстановительный), мыслитель указывает на то, что в любом случае патриотизм связан с насилием, а значит, является выражением зла:

Если хороший патриотизм состоит в том, чтобы не быть завоевательным, как говорят многие, то ведь всякий патриотизм, если он не завоевательный, то непременно удержательный, то есть что люди хотят удержать то, что прежде было завоевано, так как нет такой страны, которая основалась бы не завоеванием, а удержать завоевание нельзя иными средствами, как только теми же, которыми что-либо завоевывается, то есть насилием, убийством. Если патриотизм даже и не удержательный, то он восстановительный - патриотизм покоренных, угнетенных народов. И этот патриотизм едва ли не самый худший, потому что самый озлобленный и требуюший наибольшего насилия (Патриотизм или мир, с. 480).

Итогом размышлений о сути патриотизма становится определение его как разновидности зла. Толстой указывает на пагубность и недопустимость патриотического воспитания:

Патриотизм есть зло, которое не только не надо прививать и внушать людям, но от которого надо всеми силами избавляться (Патриотизм или мир, с. 50).

Как видим, Толстой, избегая неточности выражения своей мысли, использует ясную категоризацию патриотизма как зла. 


\section{РАЗВИТИЕ И ФУНКЦИОНИРОВАНИЕ РУССКОГО ЯЗЫКА}

Пока мы будем восхвалять патриотизм и воспитывать его в молодых поколениях, у нас будут вооружения, губящие и физическую и духовную жизнь народов, будут войны, ужасные, страшные войны, как те, к которым мы готовимся... (Патриотизм или мир, с. 50).

Однозначной негативной оценке подвергаются и функции войны:

...войны, вызывая в людях самые низкие, животные страсти, развращают, озверяют людей (Одумайтесь, с. 102).

Толстой отказывается от ранее высказанной мысли, что война объединяет людей:

Животные могут быть соединены насилием, но люди могут соединяться только одним общим для всех пониманием жизни (Не убий никого, с. 49).

Таким образом, в конце XIX - начале $\mathrm{XX}$ в. представления Толстого о войне существенно меняются. Писатель преодолевает все противоречия и приходит к однозначной негативной оценке любой войны и всего, что с ней связано. «Художественные поиски Л.Н. Толстого связаны ...c пониманием ценностной структуры мира....» [Казаков, 2009, с. 75].

Переосмысляются представления о патриотизме. Актуализируются новые знания, негативно оценивающие военную службу, милитаризацию. Расширяются концептуальные связи за счет обращения к новым концептам Власть, Государство. Считая войну злом, Толстой полагает, что порождает это зло государство и власть. Они разделяют, обманывают людей, заставляют их платить налоги, которые идут на вооружение. Концепт Война противопоставляется концептам Христианство и Любовь:

Выбирая одно из двух: христианство и любовь или государство и убийство, люди нашего времени найдут, что существование государства и убийства настолько важнее христианства, что надо забыть про христианство, а держаться только того, что важнее для людей: государства и убийства (Доклад, с. 121).

Толстой не допускает двойных стандартов в объяснении христианской заповеди не убий, настаивает на ее одинаковом применении ко всем людям:

«Не убий» не значит то, что можно убивать людей других, чем свой, народов и еще тех, убий- ство которых мы признали для себя полезным; а что слова эти ... значат то, что не должно убивать никого... (Не убий никого, с. 51).

Репрезентация воззрений на войну перенесена Толстым из художественного творчества в публицистику, которая позволяла мыслителю точно, однозначно, прямо выразить свою позицию. Лексикон писателя, направленный на репрезентацию данных представлений, становится менее фигуральным и оценочным, но более категоричным. Это, в частности, проявляется в заголовках текстов, посвященных раскрытию данной проблемы: "Не убий», "Не убий никого», «Одумайтесь!». В «военном» дискурсе Толстого усиливаются диалоговые признаки. Во-первых, писатель обращается к мнениям различных писателей, политиков для подтверждения своих мыслей: Мопассану, Чаннингу, Молинари и др. Наиболее регулярным источником цитирования является Евангелие. Формируется диалоговая ситуация, в которой Толстой подтверждает свое мнение мнением единомышленников. Во-вторых, тексты Толстого демонстрируют прямое обращение к читателю, имеют цель воздействовать на него и переубедить.

\section{5}

Итак, представления о войне, отраженные в творчестве Толстого, имеют эволюционный характер и позволяют увидеть генезис взглядов языковой личности. На ранних этапах творчества процесс осмысления войны характеризуется созерцательностью, на поздних - высокой степенью категоричности, оценочности.

\section{СПИСОК ЛИТЕРАТУРЫ}

Алефиренко Н. Ф., 1999. Спорные проблемы семантики. Волгоград : Перемена. 274 с.

Апресян Ю. Д., 1995. Лексические антонимы // Избранные труды : в 2 т. Т. 1. Лексическая семантика. Синонимические средства языка. М. : Школа «Языки русской культуры». С. $284-315$.

Волчек Д. В., 2011. Крымская война «глазами» Л.Н. Толстого и Б. Бейнбридж (по материалам «Севастопольских рассказов» и романа «Мастер Джорджи») // Вестник Пермского 
университета. Российская и зарубежная филология. Вып. 4 (16). С. 249-257.

Захаров С. В., 2016. Проблема войны и мира в публицистике Л.Н. Толстого начала ХХ в. // Царскосельские чтения : материалы Междунар. науч. конф. СПб. : ЛГУ им. А.С. Пушкина. T. 1. C. 208-214.

Казаков А. А., 2009. Авторская позиция в «Войне и мире» Л.Н. Толстого в аспекте ценностной феноменологии // Вестник Томского государственного университета. Филология. № 3 (7). С. 71-75.

Карасик В. И., Дмитриева О. А., 2005. Лингвокультурный типаж: к определению понятия // Аксиологическая лингвистика: лингвокультурные типажи : сб. науч. тр. / Под ред. В. И. Карасика. Волгоград : Парадигма. С. 5-25.

Краткий словарь когнитивных терминов, 1996. М. : Филологический факультет МГУ, 1996. $245 \mathrm{c}$.

Рикёр П., 2012. Конфликт интерпретаций. Очерки о герменевтике. М. : Какнон-Пресс-Ц. Кучково Поле. 624 c.

Степанов Ю.С., 2001. Константы. Словарь русской культуры: Опыт исследования. М. : Акад. проект. 989 с.

Токарев Г.В., 2003. Концепт как объект лингвокультурологии (на материале репрезентаций концепта «Труд» в русском языке)». Волгоград : «Перемена». 232 с.

\section{ИСТОЧНИКИ}

Война и мир - Толстой Л. Н. Война и мир // Полное собрание сочинений : в 90 т. Т. 12. М. : РГБ, 2006. C. 3-341.

Доклад - Толстой Л. Н. Доклад, приготовленный для конгресса мира в Стокгольме // Полное собрание сочинений : в 90 т. Т. 38. М. : РГБ, 2006. С. 119-125.

Не убий никого - Толстой Л. Н. Не убий никого // Полное собрание сочинений : в 90 т. Т. 37. М. : РГБ, 2006. С. 39-54.

Одумайтесь - Толстой Л. Н. Одумайтесь // Полное собрание сочинений : в 90 т. Т. 25. М. : РГБ, 2006. C. 100-148.

Патриотизм или мир - Толстой Л. Н. Патриотизм или мир // Полное собрание сочинений : в 90 т. Т. 90. М. : РГБ, 2006. С. 45-53.

Севастопольские рассказы - Толстой Л. Н. Севастопольские рассказы // Полное собрание сочинений : в 90 т. Т. 4. М. : РГБ, 2006. С. 3-119.

Хаджи Мурат - Толстой Л. Н. Хаджи Мурат // Полное собрание сочинений : в 90 т. Т. 35. М. : РГБ, 2006. С. 3-118.

\section{REFERENCES}

Alefirenko N.F., 1999. Controversial problems of semantics. Volgograd, Peremena Publ. 274 p. (in Russian).

Apresyan Yu.D., 1995. Lexical antonyms. Selected works. Lexical semantics. Synonymic means of language. Vol. 1. Moscow, Yazyki russkoy kultury Publ., pp. 284-315. (in Russian).

Volchek D.V., 2011. The Crimean war in the viewpoint of L.N. Tolstoy and B. Bainbridge (on materials of "The Sevastopol stories" and the novel "Master Georgie"). Vestnik Permskogo universiteta, iss. 4 (16), pp. 249257. (in Russian).

Zakharov S.V., 2016. A problem of war and peace in L.N. Tolstoy's journalism in the $20^{\text {th }}$ century. Tsarskoe Selo readings, vol. I, iss. XX, pp. 208214. (in Russian).

Kazakov A.A., 2009. An author's position in "War and peace" of L.N. Tolstoy in aspect of valuable phenomenology. Vestnik Tomskogo gosudarstvennogo universiteta. Filologiya, no. 3 (7), pp. 71-75. (in Russian).

Karasik V.I., Dmitrieva O.A., 2005. Linguocultural type: to definition of a concept. Karasik V.I., ed. Aksiologicheskaya lingvistika: linvokulturnyye tipazhi. Volgograd, Paradigma Publ., pp. 5-25. (in Russian).

Kubryakova E.S. et al., 1996. Short dictionary of cognitive terms. Moscow, Izd-vo Mosk. gos. un-ta. 245 p. (in Russian).

Riker P., 2012. Conflict of interpretations. Sketches about a hermeneutics. Moscow, Kaknon-Press C. Kuchkovo Pole. 624 p. (in Russian).

Stepanov Yu.S., 2001. Constants. Dictionary of the Russian culture: Experience of a research. Moscow, Akademich. Proekt. 990 p. (in Russian).

Tokarev G.V., 2003. A concept as an object of cultural linguistics (on material of representations of a concept 'Trud'in Russian). Volgograd, Peremena Publ. 232 p. (in Russian).

\section{SOURSES}

Tolstoy L.N. War and peace. Complete works: in 90 vols. Vol. 12. Moscow, RGB Publ., 2006, pp. 3341. (in Russian).

Tolstoy L.N. The report prepared for the congress of the world in Stockholm. Complete works: in 90 vols. Vol. 38. Moscow, RGB Publ., 2006, pp. 119-125. (in Russian).

Tolstoy L.N. Thou shalt not kill anybody. Complete works: in 90 vols. Vol. 37. Moscow, RGB Publ., 2006, pp. 39-54. (in Russian). 


\section{РАЗВИТИЕ И ФУНКЦИОНИРОВАНИЕ РУССКОГО ЯЗЫКА}

Tolstoy L.N. Think again. Complete works: in 90 vols. Vol. 25. Moscow, RGB Publ., 2006, pp. 100-148. (in Russian).

Tolstoy L.N. Patriotizm or world. Complete works: in 90 vols. Vol. 90. Moscow, RGB Publ., 2006, pp. 4553. (in Russian).
Tolstoy L.N. Sevastopol stories. Complete works: in 90 vols. Vol. 4. Moscow, RGB Publ., 2006, pp. 3119. (in Russian).

Tolstoy L.N. Haji Murat. Complete works: in 90 vols. Vol. 35. Moscow, RGB Publ., 2006, pp. 3-118. (in Russian).

\section{Information about the Author}

Grigoriy V. Tokarev, Doctor of Sciences (Philology), Professor, Head of Department of Document Studies and Stylistics of the Russian Language, Tula State Lev Tolstoy Pedagogical University, Prosp. Lenina, 125, 300026 Tula, Russia, grig72@mail.ru, http://orcid.org/0000-0002-2362-0902

\section{Информация об авторе}

Григорий Валериевич Токарев, доктор филологических наук, профессор, заведующий кафедрой документоведения и стилистики русского языка, Тульский государственный педагогический университет им. Л.Н. Толстого, просп. Ленина, 125, 300026 г. Тула, Россия, grig72@mail.ru, http://orcid.org/0000-0002-2362-0902 